up in expiration and falls in inspiration. This is protected by a metal cap (D) when the inhaler is not in use. The cone is covered with red flannel, and has a white flannel bag, which is removable, placed within it, and upon this the chloroform is sprinkled through an opening in the cone, $B$. This bag is open at the small end of the cone. When the cone is placed upon the patient's face the respiratory indicator readily shows the rhythm and force of the respiratory movements, and is unquestionably a useful contrivance. The pendant position of the feather indicator can be adjusted to suit the position of the patient's face by turning the cylinder in the desired direction. We have tried the cone and find it answers very well, and can speak favourably of it for the A.C.E. mixture. Those who like a cone in giving chloroform will find Krohne and Sesemann's a great improvement upon the ordinary one in use. The indicator, provided it is not allowed to take the place of close attention to the patient's condition, is a valuable adjunct, and when understood affords reliable evidence of the activity of the patient's respiration. We say when understood, because it is possible by shaking or pinching in the inhaler to produce movements of the register which might mislead the unwary. This objection, if it be one, is so slight as to fall into insignificance when compared with the undeniable utility of the inhaler.

\section{SULPHUR FUMES APPARATUS.}

From time to time reference is made in the medical press to this old treatment of diphtheria. The plan usually adopted is to heat an iron shovel, put sulphur on it, and get the patient to inhale the fumes. The disadvantages of this plan are that the nurse gets most of the fumes, and the child, if obstinate and unmanageable, has but a small share of them. Another drawback is that a struggling child might easily be burnt by the hot shovel. In order to obviate all this $\mathbf{I}$ have devised a simple apparatus which will be found useful for this treatment. It consists of a stand (A) with a spirit lamp which heats the sulphur in the drawer (B); the fumes pass up the chimney (C), and by means of the tubing, to which a mouthpiece (D) is attached, they are conducted

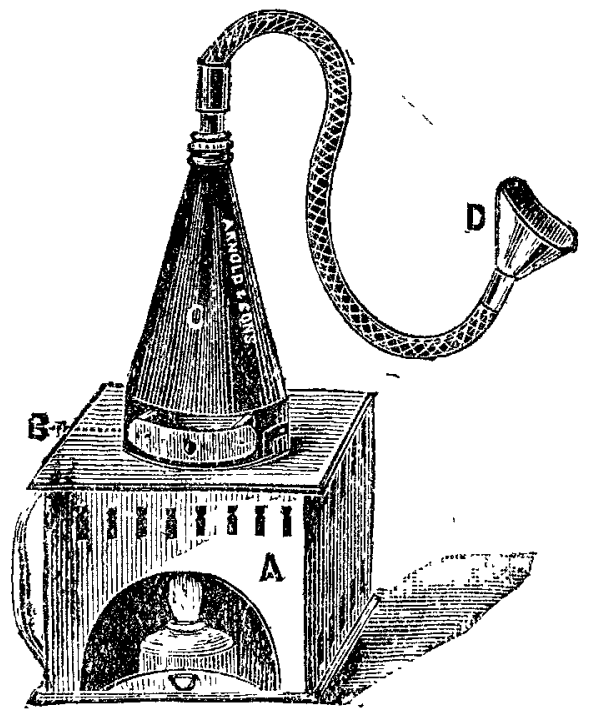

to the patient. A teaspoonful of sulphur sublimatum is placed in the drawer, and when the fumes begin to appear, at the mouthpiece, it is held near, and a little below the mouth (not over it), because some air space is necessary, as the fumes are acrid and irritating, and should not be inhaled undiluted. The fumes should be inhaled for two or three minutes, the patient inhaling through the mouth and exhaling through the nose. This is to be done every two hours at first, and less frequently later. The eyes should be covered with a handkerchief to prevent the conjunctivæ being irritated. The apparatus has been made for me by Messrs. Arnold and Sons, West Smithfield, London.

Eastbourne. JAMES ADAMS, M.D., F.R.C.S.

\section{THE ASSOCIATION OF FELLOWS OF THE ROYAL COLLEGE OF SURGEONS OF ENGLAND.}

A WELL-ATTENDLD meeting of the Committee of the Association of Fellows of the Royal College of Surgeons of England was held at 5 T.M. on Wednesday, June 24th, at 36, Grosvenor-street. The secretary, Mr. Percy Dunn, reported that be had issued the circular drawn up by the Committee and sent out postcards to members of the Association, and he had received two resignations from gentlemen officially connected with the College and several new proposals for admission to the Association. The Fellows thus applying were elected members, and the financial position of the Association was dis. cussed. The income and expenditure for the preceding year were nearly equal, amounting to about $£ 23$ in both cases. The arrangements for the general meeting having been settled, the meeting terminated.

The annual general meeting of the Association was held on Thursday, June $25 \mathrm{th}$, at the rooins of the Medical Society in Chandos-street. Mr. Pollock, the president, occupied the chair, and was influentially supported. The secretary having read the minutes of the last meeting, the officers and committee of the Association were unanimously reelected, on the motion of Mr. J. A. McDonagh and Mr. Holmes. The President then gave a résumé of the work of the Association during the past year, including the proceedings in reference to the deputation of the Committee of the Association to the Council of the College and the issue of this recent circular of the committee. All that the Association has done has been fully reported and discussed in the columns of THE LAxCET. Dr. Collins pro. posed, and Mr. Morgan seconded, the following resolution, which was carried unanimously: "That the Association of Fellows of the Royal College of Surgeons objects to the acquisition of any new powers by the College in the matter of conferring medical degrees, unless and until the Fellows of the College shall have had an opportunity of expressing their opinion thereon. That copies of this resolution be forwarded to the Lord President of the Council, the Chancellor of the University of liondon, the Chairman of Convocation of the University of London, and the President of the Royal College of Surgeons." Mr. Holmes, in moving a. vote of thanks to the President, touched upon the importance of the Association continuing to press for the concession of separate meetings of Fellows and a common room, as well as the necessity for securing the election into the Council of Fellows who could be relied on to support amendments in the constitution of the College. Mr. Tweedy seconded the resolution, referring to the calm and sustained interest taken by the President in the affairs of the Association. The resolution was carried by acclamation. It was further proposed by Mr. Holmes, and seconded by Mr. Wickham Barnes " that the secretary be instructed to write to the President and Council of the Royal College of Surgeons, reminding them that they have now received an authoritative legal opinion in favour of the course which this Association requested them to take as to summoning meetings of the Fellows separately from the Members, and respectfully begging them for a definite answer on the subject."

Medico - Psychological Association. - The fiftieth (jubilee) annual meeting of the Association will be held on Thursday, July 23rd, at the City Asylum, Birmingham, under the presidency of Edmund $B$. Whitcombe, M.R.C.S Dr. Yellowlees will move: "That, with a view" to secure greater uniformity, the examinations for the Asso. ciation's certificate in medico-psychology shall be conducted on the same system as those for the certificate in nursing: that is to say, that the papers shall be set and valued by the examiners of the Association acting conjointly; that the written examinations shall be held on the same day throughout the country, the sealed questions being opened at the hour of examination; and that the clinical and oral examinations shall be held at any convenient time thereafter, by the examiners for the respective countries, when they have examined and assessed the written papers." 